\title{
Keynotes
}

\section{Beyond the water tower: current demands upon consultant psychiatrists}

\author{
Andrew Sims, President, Royal College of Psychiatrists; Professor of Psychiatry, \\ University of Leeds
}

\begin{abstract}
"There they stand, isolated, majestic, imperious, brooded over by the gigantic water tower ... the asylums which our forefathers built with such immense solidity to express the notions of their day. Do not for a moment underestimate their powers of resistance to our assault" (Enoch Powell, 1961).
\end{abstract}

The assault has partly succeeded and the inertia of mind has been overcome. However, many mental health professionals, ministers and members of parliament, and others concerned with management have looked with considerable anxiety at what they see beyond the water tower. This has been forcefully expressed:

"It would be tragicindeed if those who extol the virtues of community care so vigorously and at times uncritically merely encourage it into being discredited as a result of the escalating number of clinical tragedies and inadequately treated disturbances due to mental illness in the community: The end result would be loss of society's tolerance and hasty reversion to institutional care of the worst kind" (Morgan, 1992).

Enoch Powell's approach to the treatment of the mentally ill demanded new premises, preferably in District General Hospitals. New premises demand new services, but most of the health professionals and managers who are now called upon to deliver them have had no specific training for this, nor experience. New services demand a redeployment of resources but far too often at least part of the precious capital and revenue has disappeared elsewhere into the voracious maw of the Health Service. New opportunities for treatment demand, in sufficient numbers, those able to provide them.

Better Services for the Mentally Ill aimed to create a local comprehensive mental illness service in each health district, and to close hospitals which were not well placed to provide such a local service. This has not yet produced better care for patients uniformly because it stops short of the essential feature of the National Health Service, the provision of a personal physician to care for the individual patient. For these therapeutic relationships to be established, the contractual arrangements should give consultants control of resources for their clinical service so that they can provide individual treatment and aftercare for patients. There is an optimum number of patients any consultant can reasonably look after and if this is exceeded the quality of service inevitably deteriorates.

There are many justifiable and sometimes competing demands for resources, and because one particular need is emphasised others are not denied. It is claimed that the present mediocrity of community psychiatric services in Britain can only be improved by a substantial increase in the number of trained psychiatrists. In comparing psychiatric services in Australia with New Zealand in 1987, Andrews (1989) demonstrated that Australian psychiatrists were seeing more patients, giving each patient more time, treating more patients in the community, and more often providing psychological methods of treatment. There were twice as many trained psychiatrists in Australia per 100,000 population but the service was provided at only two-thirds of the cost of New Zealand. In England and Wales, we have not yet achieved the consultant staffing of New Zealand in 1987.

\section{What are the new demands upon consultant psychiatrists?}

Why is there now a need for more consultant psychiatrists? This question was asked of the eight Sections of the Royal College of Psychiatrists and it became clear that there are both general and specific reasons. To begin with general factors:

1. The momentum for community care in initiating locally based services has practical advantages for patients in terms of increasing the availability of treatment and lessening the stigma. However, an inevitable consequence is that, because of travelling time and dealing with more people, it takes the doctor more time to see each patient. Improved availability and less stigma has 
TABLE I

Psychological Management

Depressive disorder (neurotic depression)

Neurotic, stress-related, and somatoform disorders

Physiological dysfunction associated with mental or behavioural factors

Abnormalities of personality, behaviour and relationships

Behavioural modification of aspects of behaviour in schizophrenia, dementia and mental handicaps

Work with family and carers

encouraged more patients to present for treatment. There are also more colleagues in different disciplines with whom to liaise when working in the community.

2. Changes in the National Health Service, in part resulting from Working for Patients, have resulted in altered working patterns for doctors, giving less time to see patients for the reasons below; more doctors are therefore required for patient care. Clinical audit is a welcomed improvement but makes demands upon time. This also pertains for implementation of the Department of Health's initiative on the Care Programme. Increasingly, management with a Clinical Directorate in a mental health unit or psychiatric service is established; this requires sessional time from the clinical director and cover for these duties by the other consultants. Arrangements for assimilating the much needed reduction in junior doctor hours will increase the workload of consultants.

It is imperative that with the introduction of new effective methods of treatment for psychiatric disorders and the implementation of a radically different method of delivering psychiatric services, consultants have the opportunity to maintain their existing knowledge and skills and learn new methods; the Royal College of Psychiatrists has recently recommended expansion of continuing education programmes for consultants. The need for more clinical research in psychiatry has been recommended by the Director of Research and Development of the National Health Service Management Executive. Both of these admirable objectives require consultant time.

3. Applying mental health and other legislation is an important part of the work of the consultant psychiatrist. The Mental Health Act (1983) has made increased demands upon consultants, both directly in the preparation of reports for Mental Health Review Tribunals, and indirectly in that there are 24 medical members of the Mental Health Act Commission and releasing them for this work creates an increased demand upon their local colleagues. Much other recent legislation also increases the work of psychiatrists; to highlight but one, the Children Act has resulted in considerable work, not only for child psychiatrists but for many other consultant psychiatrists.

4. One of the most encouraging developments in modern psychiatry is the introduction of new psychological methods of treatment with welldesigned research studies showing efficacy (Szmukler, 1990). Some of the conditions and situations that may be so treated are summarised in Table I, using the International Classification, 10 th edition. Several methods of psychotherapy involving psychodynamic, cognitive and behavioural strategies have been introduced over the last couple of decades; the methodology for evaluating the results of treatment is often complex and requires further sophistication, but in many instances the effectiveness of such treatments has been demonstrated. Such developments are a significant demand upon psychiatric time; with new effective treatments more patients present or are referred for treatment. Of course, these treatments are not always effective, neither are they provided only by psychiatrists, but psychiatrists are trained to assess suitability for and to deliver them, and often the best results are achieved by a combination of pharmacological and psychological treatments.

\section{Demands upon the specialties within psychiatry}

The specialties within psychiatry are shown in Table II. There are specific factors which have increased the demands upon consultant psychiatrists in each of these specialties.

In general psychiatry, sectorisation, where one or very few consultant psychiatrists serve all the general psychiatric needs of a geographically designated sector within the health district, provides a more local service to patients, but makes very considerable demands upon the consultants. The greater range of effective treatments has particularly increased the workload of general psychiatrists, both because the treatments themselves are time-consuming and their availability has resulted in more patients. 
TABLE II

Specialties within psychiatry

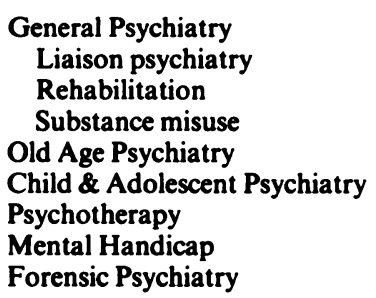

Working in the community necessitates liaising with those in other health disciplines, and the supervision of the work of junior doctors and others is more time consuming when conducted outside the hospital. The current, welcomed emphasis on quality assurance in medical practice is also more difficult to carry out in the community. Greater attention given to preventive issues in psychiatry by Government represents progress; this is beneficial for patients, but time consuming for the consultant.

Liaison psychiatry is rapidly expanding and provides psychiatric services to non-psychiatric specialties in general hospitals. It can offer treatment for patients with somatic symptoms without organic disorder, for psychogenic symptoms associated with physical illness, and a safe, effective and rapid service for patients manifesting deliberate self-harm. There has been a considerable increase in patients presenting for treatment of eating disorders, both anorexia and bulimia nervosa, and, as treatment can be effective when carried out by well trained specialists, there is an increasing need for consultants.

Current practice has changed greatly in psychiatric rehabilitation and the treatment of the chronically mentally ill. The majority of such patients now live outside hospital, in the community; it is imperative that there are sufficient staff to ensure continuing care. There is a need for psychiatrists to provide continuity of treatment after discharge, to monitor the mental state and ensure medication is appropriate, and to work with general practitioners, community psychiatric nurses and others in maintaining an optimum level of physical and mental health, social satisfaction and comfort. Traditionally far too little time was made available for the management of the longstay mentally ill and there is an evident need for more consultant staffing. There is also lack of academic input into community care of the long-term ill, a need for more training of medical and other staff, and for research in this area.

In most parts of the country treatment services for substance misuse are rudimentary, and in many Districts there are no designated consultant sessions for the treatment of dependence upon alcohol and other substances. The number of sufferers from alcohol related problems is very great; a high proportion remain undiagnosed and even more untreated although intervention can be effective. This represents a huge cost to the nation. There is a need for specialist services to support primary agencies in treatment. Early professional intervention for drug misuse in young people may be effective; provision of services will help to lessen injection transmitted infections. There is also a need for treatment services for benzodiazepine dependence.

Old age psychiatry requires increased consultant staffing as there are still many areas with no specifically designated service, and many others are grossly understaffed. The Old Age Section of the Royal College of Psychiatrists believes that stress and overwork has resulted in consultants dying prematurely or taking early retirement. Demographic changes in the population, increased expectations by relatives, and the introduction of care in the community has resulted in an increased workload. Psychiatric problems occurring in medically ill patients and the changing pattern of geriatrics requires greater availability of psychogeriatric assessment and treatment. To an increasing extent chronically ill patients, mostly suffering from schizophrenia, who were previously treated in mental hospitals are now growing old in the community and may require the services of an old age psychiatrist.

There has been a dramatic increase in the amount of work for consultants in child and adolescent psychiatry. Since publication of the report Bridges over Troubled Waters there has been an intention to extend adolescent services to the age of 18 . Mentally handicapped children with psychiatric disorders are increasingly the responsibility of child psychiatrists. The identification, and hence requirement for treatment, of child abuse and neglect, especially child sexual abuse, has greatly increased. Child psychiatrists are often involved in the placement of difficult and disturbed children; this requires considerable consultant time. The Children Act, now being implemented, makes enormous demands upon child and adolescent psychiatrists. Family breakdown, which has greatly increased, often results in emotional disturbance among affected children and this requires treatment. The decrease in residential care accommodation for children has resulted in increased psychiatric referral. Most substance misuse among adolescents, which has increased in recent years, is treated in child and adolescent services. In many parts of the country adolescent services are grossly inadequate, and sometimes non-existent; there is a need to produce uniform services nationally. There is an increased demand for multidisciplinary teaching to other professions concerned with the care of children.

There is at present gross geographical disparity in the provision of psychotherapy services nationally, 
with large areas, sometimes amounting to health regions, unprovided with specialist consultant psychotherapists. Developments in psychological management, increased demands from patients, and the introduction of community care require provision of better services. Consultant psychotherapists have a crucial role to play in the training of other psychiatrists and mental health professionals. Psychotherapy services also have a role in occupational health for National Health Service personnel; this could prove to be cost effective.

In the psychiatry of mental handicap, community work is particularly time-consuming as the communication of their symptoms by patients is laborious. Parents' expectations for treatment of themselves and their mentally handicapped offspring has considerably increased in recent years. In this specialty community care has made great progress, and this has resulted in increased demands from socially disabled people with milder mental handicap. At present much work is being carried out by non-training grade doctors, and it is intended eventually to replace these with consultants. There is lack of staff in other disciplines concerned with learning difficulties, for example, a severe shortage of clinical psychologists; this results in increased work for consultants in the specialty. There was poor recruitment in the specialty for perhaps two decades until the last few years; this has resulted in a high average age for current consultants and therefore many retirements are imminent.

In forensic psychiatry a considerable expansion of the consultant grade has been predicted for the near future. This will become more apparent and quantifiable when the Review of Health \& Social Services for Mentally Disturbed Offenders reports in 1992. Schemes for the diversion of mentally abnormal offenders from custody, developments for the prison medical service, and the proposal to provide forensic psychiatric sessions in local Courts will all require National Health Service consultant psychiatrists to achieve their aims. Regional Secure Units are far short of their recommended number of beds nationally; but there is evidence that this number should be further increased beyond the original Butler recommendations, with consequent needs for consultants.

Consultant psychiatrists working in Special Hospitals currently look after an excessive number of patients, and it is proposed to decrease this case-load. It has also been recommended that there should be a general psychiatrist with a special interest in forensic psychiatry in each District, which will require additional staffing. Closure of psychiatric hospitals has led to an increased number of long-stay, difficult to place patients being found outside the large institutions, this has made considerable demands upon forensic psychiatry.

\section{Conclusions}

There are now more biological and psychosocial treatments of proven efficacy in psychiatry than have been available previously. Much psychiatric treatment is time-consuming and requires highly skilled manpower. The change from institutional to community care, changes in the National Health Service and in legislation have greatly increased the consultant workload, and there are considerable demands upon consultants for teaching and research. It has been demonstrated outside the United Kingdom that the delivery of a psychiatric service with twice the number of trained psychiatrists can provide more community care at two-thirds of the cost; the Royal Australian and New Zealand College of Psychiatrists is now recommending one trained psychiatrist per 7,500-10,000 population and the Canadian Psychiatric Association 1 per 8,000, both of these are three times the current provision in the United Kingdom.

In order to transfer expenditure from institutional care to community care there is a need for bridging finance to cover the changes and control of the resources by mental health services. With the present rapid run down of psychiatric hospitals and inpatient beds, unless there is a corresponding increase in the number of psychiatrists, not only will the quality of present psychiatric services not be maintained, but they will deteriorate. There is an urgent need for very considerable expansion of the consultant grade.

\section{Acknowledgements}

I am grateful for the information of this paper to the honorary secretaries of the specialist sections of the Royal College of Psychiatrists: Dr S. M. Benbow, Dr T. Burns, Dr R. V. Cope, Dr S. M. Grant, Professor J. H. Lacey, Dr C. Lindsey, Dr E. B. Ritson and Dr D. Wilson.

\section{References}

ANDREws, G. (1989) Private \& public psychiatry: a comparison of two health care systems. American Journal of Psychiatry, 146, 881-886.

MorGaN, H. G. (1992) Suicide prevention: hazards on the fast lane to community care. British Journal of Psychiatry, 160, 149-153.

PoWELl, E. (1961) Emerging Patterns for the Mental Health Services and the Public. London: National Association for Mental Health.

SzMUKLER, G. I. (1990) Alternatives to hospital treatment. Current Opinion in Psychiatry, 3, 273-277.

A full list of references is available on request to Professor Sims. 